\title{
The Eddy Kinetic Energy Budget in the Red Sea
}

Peng Zhan ${ }^{1}$, Aneesh C. Subramanian ${ }^{2}$, Fengchao Yao ${ }^{3}$, Aditya R.

Kartadikaria $^{1}$, Daquan Guo ${ }^{1}$, and Ibrahim Hoteit ${ }^{1}$
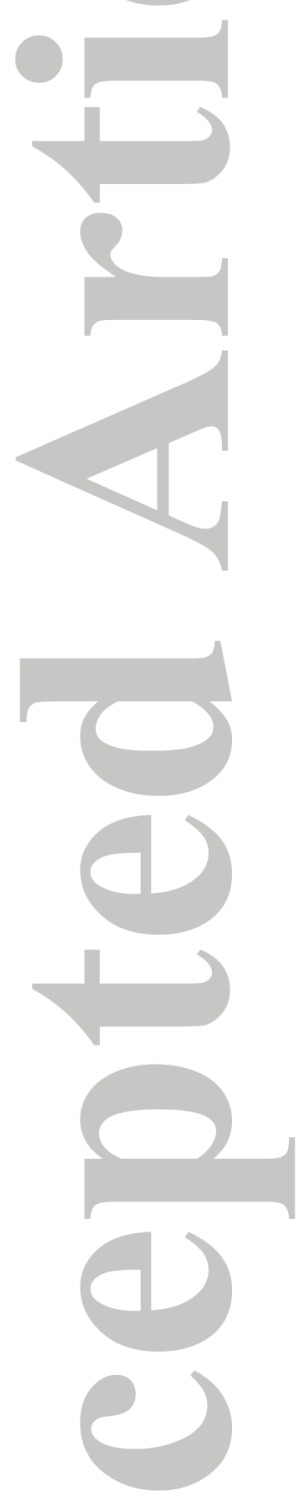

This article has been accepted for publication and undergone full peer review but has not been through the copyediting, typesetting, pagination and proofreading process which may lead to differences between this version and the Version of Record. Please cite this article as doi: 10.1002/2015JC011589

(C) 2016 American Geophysical Union

Received: Dec 19, 2015; Revised: Jun 03, 2016; Accepted: Jun 06, 2016 


\section{Key Points}

Main point 1: The first study of eddy energy budget in the Red Sea.

Main point 2: Study the mechanisms of eddy seasonal variability in the Red Sea.

Main point 3: Baroclinic instability is identified to be the main source of EKE in the Red Sea.

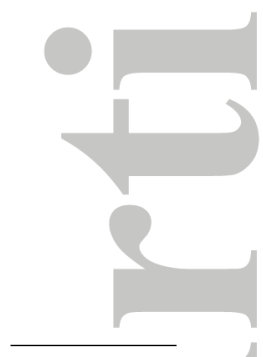

Corresponding author: Ibrahim Hoteit, Division of Physical Sciences and Engineering, King Abdullah University of Science and Technology, Thuwal, Saudi Arabia. (ibrahim.hoteit@kaust.edu.sa)

${ }^{1}$ Division of Physical Sciences and

Engineering, King Abdullah University of

Science and Technology, Thuwal, Saudi

Arabia.

${ }^{2}$ Clarendon Laboratory, University of

Oxford, Oxford, UK.

${ }^{3}$ Red Sea Research Center, King Abdullah

University of Science and Technology,

Thuwal, Saudi Arabia.

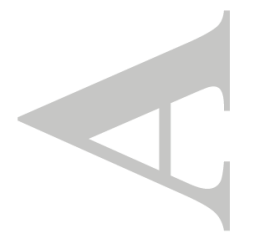


Abstract. The budget of eddy kinetic energy (EKE) in the Red Sea, including the sources, redistributions and sink, is examined using a high-resolution eddy-resolving ocean circulation model. A pronounced seasonally varying EKE is identified, with its maximum intensity occurring in winter, and the strongest EKE is captured mainly in the central and northern basins within the upper $200 \mathrm{~m}$. Eddies acquire kinetic energy from conversion of eddy available potential energy (EPE), from transfer of mean kinetic energy (MKE), and from direct generation due to time-varying (turbulent) wind stress, the first of which contributes predominantly to the majority of the EKE. The EPEto-EKE conversion occurs almost in the entire basin, while the MKE-to-EKE transfer appears mainly along the shelf boundary of the basin (200 $\mathrm{m}$ isobath) where high horizontal shear interacts with topography. The EKE generated by the turbulent wind stress is relatively small and limited to the southern basin. All these processes are intensified during winter, when the rate of energy conversion is about four to five times larger than that in summer. The EKE is redistributed by the vertical and horizontal divergence of energy flux and the advection of the mean flow. As a main sink of EKE, dissipation processes is ubiquitously found in the basin. The seasonal variability of these energy conversion terms can explain the significant seasonality of eddy activities in the Red Sea.

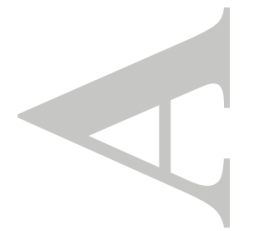




\section{Introduction}

The Red Sea basin is about $1930 \mathrm{~km}$ long and $280 \mathrm{~km}$ wide on average, with a surface area of roughly $450000 \mathrm{~km}^{2}$. The average depth is about $490 \mathrm{~m}$, but a deep trench in the middle of the basin records a maximum depth of about $2920 \mathrm{~m}$ [Gerges, 2002; Rasul and Stewart, 2015]. As the only significant connection between the Red Sea and the global ocean, the Strait of Bab-al-Mandeb is a 25- $\mathrm{km}$ wide channel with a sill depth of about 137 $m$ [Werner and Lange, 1975]. The water exchange through this narrow strait compensates for the heat and freshwater fluxes in the Red Sea, and greatly affects the circulation in the southern basin [Yao et al., 2014a, b; Sofianos and Johns, 2015].

Despite its narrow basin, the Red Sea exhibits a strong lateral variability in circulation associated with boundary currents and eddies. The main forcing that drives the circulation in the Red Sea is related to the seasonally varying buoyancy flux and wind regime [Tragou and Garrett, 1997], under which a different pattern of circulation prevails in summer and in winter, respectively [Yao et al., 2014a, b]. The different studies of Red Sea circulation are not always in consistent with each other, however, two key features of circulation have been reported, including the remarkable seasonal variability and the rich eddy activities in the basin [Sofianos and Johns, 2003; Yao et al., 2014a, b; Zhan et al., 2014].

The depth of thermocline is about $30 \mathrm{~m}$ to $60 \mathrm{~m}$ in summer [Sofianos and Johns, 2007], and in winter, the basin north of $25^{\circ} \mathrm{N}$ exhibits a thermocline depth that exceeds $200 \mathrm{~m}$ or more [Edwards, 1987]. Below the thermocline the water is fairly uniform in the salinity and temperature of about $40.6 \mathrm{psu}$ and $21.5^{\circ} \mathrm{C}$, respectively [Edwards, 1987]. The general pattern of mean surface temperature is decreasing from south to north with a significant 
seasonal cycle in the upper layers. The average surface temperature in February and in July respectively ranges from $17.5^{\circ} \mathrm{C}$ to $27^{\circ} \mathrm{C}$ and from $26^{\circ} \mathrm{C}$ to $32^{\circ} \mathrm{C}$ [Edwards, 1987]. The annual mean surface salinity increases with latitude from $36.5 \mathrm{psu}$ near the Strait of Bab-al-Mandeb to 40.5 psu at the northern end of the basin, yet the seasonal variation of salinity in this region is not well documented.

Eddies play a key role in the ocean dynamics, contributing to the regulation of the biogeo-chemical cycle in the ocean. The kinetic energy (KE) of eddies is usually an order of magnitude larger than that of mean flow [Richardson, 1983; Ferrari and Wunsch, 2009], and eddies are integral to the energy conversions between the large-scale circulation and the mesoscale (sub-mesoscale) dynamics. Previous studies have shown that eddies are one of the key features of hydrodynamics in the Red Sea [Eshel and Naik, 1997; Sofianos and Johns, 2003, 2007; Zhan et al., 2014]. The eddy-associated transports are reported to be several times greater than the mean overturning transport [Bower and Farrar, 2015], and the intensity of eddies may affects deep-water formation and overturning circulation in the basin [Papadopoulos et al.]. In addition, eddies in the Red Sea also have a strong impact on the marine ecosystem: the eddies' relatively well-maintained integrities and energetic flow allow them to transport nutrients, heat, carbon, and other biogeochemical particles from one coast to the other, processes sometimes enhanced by a series of flanking eddies, and vertically eddy-induced pumping brings nutrient-enriched subsurface water into the euphotic zone to help sustain primary production [Zhai, 2014; Xiu and Chai, 2011; Stramma et al., 2013].

Although a number of studies have investigated the mechanisms of eddy generation in the Red Sea, no consensus has been reached. Clifford et al. [1997] reported that the 
formation of eddies in the Red Sea is largely affected by wind direction, and a few years later, Sofianos and Johns [2003], reproduced a cyclonic eddy in the northern Red Sea using the Miami Isopycnal Coordinate Ocean Model forced only by loss of surface buoyancy. More recently, Chen et al. [2014] analyzed the outputs of a Finite-Volume Community Ocean Model and concluded that an anticyclonic eddy in the central Red Sea is formed mainly by buoyancy forcing. Zhai and Bower [2013] identified the dipole eddy system near $18-19^{\circ} \mathrm{N}$ as an ocean response to the Tokar Wind Jet using observations and an idealised numerical model of the Red Sea. And Zhai [2014] discussed other possible mechanisms as the source of eddy generation in the Red Sea including baroclinic instability, bottom topography, cross-basin wind and meridional varying buoyancy forcing.

In this study, we investigate the mechanisms of eddy generation in the Red Sea particularly by analyzing the budget of eddy kinetic energy (EKE), and estimate the relevant eddy energy conversions and distributions in different seasons. Limited spatial and temporal coverage of oceanic data in the Red Sea makes it difficult to study and understand the role of eddies in the region based solely on observations. Thus, numerical simulations for the Red Sea using an eddy-resolving general circulation ocean model would greatly expand the data available and enable us to estimate the energy flow of eddies in the basin. Similar numerical studies have proven to realistically reproduce many features of eddy energy in oceans. von Storch et al. [2012] estimated the full Lorenz energy cycle for the world's oceans based on STORM/NCEP simulation. Eden and Böning [2002] studied the seasonally varying eddy field using a North Atlantic general circulation model, identifying the source of EKE as mainly generated through barotropic instability when the west Greenland current interacts with the steep topographic slope. Xie et al. [2007] analyzed 
the outputs of a Hybrid-Coordinate Ocean Model (HYCOM) and concluded that isobathic curvature is central to enhancing barotropic and baroclinic energy transfer rates from the Gulf Stream to its meanders and eddies. Shore et al. [2008] examined the sources of eddy energy in the Gulf of Alaska using an assimilated model and found that both barotropic and baroclinic instabilities contribute to the substantial production of EKE. Zhai et al. [2010] used a simple reduced-gravity model to study the sink of eddy energy near western boundaries where energy is found probably scattered into high-wavenumber vertical modes and caused energy dissipation as well as diapycnal mixing. Zhai and Marshall [2013] also examined the generation of eddy energy and energy fluxes in the North Atlantic using the MIT general circulation model $(\mathrm{MITg} \mathrm{cm})$ and found that eddies release available potential energy ubiquitously in the upper ocean, and that vertical eddy energy flux redistributes the eddy energy differently in the subpolar and subtropical gyres. Yang et al. [2013] conducted an eddy budget analysis in the South China Sea based on the outputs of LASG/IAP (State Key Laboratory of Numerical Modeling for Atmospheric Sciences and Geophysical Fluid Dynamics/Institute of Atmospheric Physics) Climate system Ocean Model (LICOM) and pointed out that the energy released from baroclinic instability, barotropic instability and that transported by horizontal convergence are the three main sources of EKE, and that the generated energy is mainly balanced by turbulent viscosities.

To approach the EKE budget, we used outputs of a long-term eddy-resolving general circulation model to analyze the sources, redistributions and sink in the basin with a spatial and temporal quantitative description of eddy energy status. This paper is organized as follows. Section 2 briefly describes the ocean model, and Section 3 presents the first calculation of eddy energy conversion from the mean circulation. The details of sources, 
redistributions and sink of eddy energy and the relevant nature of the energy conversions are analyzed in Section 4. A discussion and summary of the main results are given in Section 5 .

\section{The Model}

We used a high-resolution MITgcm [Marshall et al., 1997] configured for the Red Sea [Yao et al., 2014a, b]. The model domain extends from $10^{\circ} \mathrm{N}$ to $30^{\circ} \mathrm{N}$ and from $30^{\circ} \mathrm{E}$ to $46^{\circ} E$, including the Red Sea basin, the Gulf of Suez, the Gulf of Aqaba and part of the Gulf of Aden. The model is implemented with a horizontal resolution of about $1.8 \mathrm{~km}$ and 40 vertical levels, with the vertical resolution varying between $10 m$ at the surface and 150 $m$ near the bottom. This resolution is fine enough to resolve the mesoscale eddies in the Red Sea given that the first baroclinic Rossby radius of deformation ranges from $10 \mathrm{~km}$ to $40 \mathrm{~km}$ in the basin (not shown). The model was integrated with a time step of $300 \mathrm{~s}$. The model is forced with six hourly atmospheric fields from the European Centre for MediumRange Weather Forecasts (ECMWF) with a horizontal resolution of $0.75^{\circ}$, which greatly reduces the potential shortcomings of using low-resolution or climatological products as indicated by Bower and Farrar [2015]. The eastern open boundary is specified with an ocean reanalysis from the Estimation of the Circulation and Climate of the Ocean (ECCO) project [Köhl and Stammer, 2008]. After spinning up of 27 years, the model outputs were saved every 3 days. In this study, we analyzed 20 years of model outputs from 1981 to 2000. This model has been validated and used previously to study the seasonal overturning circulation in the Red Sea and water exchange with the Gulf of Aden. Details of the model configurations can be found in Yao et al. [2014a]. 


\section{Distribution of EKE and Energy Transfer}

The four main mechanical energy reservoirs in the ocean are mean kinetic energy (MKE), mean available potential energy (MPE), EKE, and eddy available potential energy (EPE) [von Storch et al., 2012; Xie et al., 2007]. Although it is not possible to calculate the exact MPE and EPE, given the various approximations of numerical models, one is able to calculate the conversion rates and study the transfers among these energy components [von Storch et al., 2012]. To start, we focus on EKE, which is the most direct estimate of eddy intensity.

\subsection{Distribution of EKE}

Eddies are generally represented by perturbations from a long-term mean of a quasisteady flow. In the Red Sea, however, the background flow is closely linked to seasonality [Yao et al., 2014a, b; Sofianos and Johns, 2003]. Consequently, the question of how to characterise the eddies activities in the Red Sea immediately arises. Thus, to separate the signal from the seasonally varying flow, eddies are defined as perturbations from a climatological monthly mean flow. It should be noted that the inter-annual signal is included in the EKE under such definition of eddies. However, spectrum analysis (not shown) indicates that, compared to the dominant seasonal variability, the inter-annual variability is much weaker and could be neglected.

The EKE is calculated as $\frac{1}{2}\left(\overline{u^{\prime 2}}+\overline{v^{\prime 2}}\right)$, where the overbars and primes denote time averages and deviations from the means, respectively. Figure 1 shows the basin-averaged vertical profiles of MKE and EKE in winter (a) and summer (b). Considerably higher EKE values suggest that eddies are more energetic than the mean flow. Note that the EKE is confined to the upper layers with the most energetic eddy activities occurring in winter. 
Figure 1 (c) and (d) show the spatial distribution of 200m-integrated EKE in winter and summer, respectively. The EKE in the southern Red Sea is relatively moderate compared to that in the northern basin. It increases substantially in the central and northern basins during winter, exhibiting a northward increasing gradient. The highest intensity of the winter EKE appears in the interior basin of the Red Sea between $24^{\circ} N$ and $26^{\circ} N$, where the most intense signals exceed $6 \times 10^{3} \mathrm{Jm}^{-2}$, noticeably higher than that in summer.

Compared to the results calculated using AVISO remote sensing data [Zhan et al., 2014], which reported high EKE in the central Red Sea between $20^{\circ} \mathrm{N}$ and $24^{\circ} \mathrm{N}$, the model indicates a higher EKE location in the northern basin. This discrepancy comes from the statistical analysis results of the EKE calculated using between gridded sea level anomaly (SLA) and velocities from model outputs, with different definitions of eddies. The EKE from AVISO is calculated based on the eddies captured from geostrophic velocity anomalies with respect to a 7-year mean sea surface [Le Traon and Dibarboure, 1999; Ducet et al., 2000; Zhan et al., 2014]. Considering the resolution of the gridded product, those eddies with a radius smaller than $35 \mathrm{~km}$ are not represented. In this study, however, the model EKE is calculated based on perturbations of velocities from the climatological monthly mean flow, using the outputs of a high-resolution MITgcm. The discrepancy may also result from underestimating the intensities of eddies using a merged AVISO product [Zhai and Bower, 2013], possibly due to the relatively low spatial and temporal coverage of the satellite tracks in the basin, but also because the satellite may not adequately capture narrow and relatively small scale eddies [Zhan et al., 2014; Bower and Farrar, 2015]. In addition, the coarse-resolution ECMWF forcing may not fully reproduce the 
orography-caused coastal mountain gap wind jets [Jiang et al., 2009], which may also affect the eddy field.

\subsection{Eddy Energy from the Mean Circulation}

To determine why EKE is highest in the central and northern basins, and to identify the cause of the seasonality in the eddy field, we examined the possible mechanisms associated with eddies formation. In a closed basin, eddies can be generated in different ways: by direct wind forcing, by topographic steering and through instabilities of the mean currents [Shore et al., 2008; Zhai and Marshall, 2013]. To examine the direct wind effect, we implemented an experiment forced with only wind from the atmosphere and discovered that eddy activities faded away upon removal of the buoyancy fluxes (not shown). Next, we considered that topographic steering could be an important factor in the northern basin where the northward eastern boundary current may be circuited by the enclosed coastline. This, however, occurs only in the offshore regions yet not in the deep interior basin. We have verified that the necessary conditions for the baroclinic and barotropic instabilities [Vallis, 2006; Olbers et al., 2012] are met in the Red Sea basin (not shown). We may therefore reasonably consider the major eddy energy source is obtained from the available potential energy or the KE in the mean flow, and expect the energy is converted between mean flow and eddies through instabilities.

The perturbation flow may extract energy from the mean flow through instabilities [Pedlosky, 1992]. To examine the eddy energy contribution from different sources, as noted by Eden and Böning [2002], the energy conversion terms,

$$
B C=-\frac{g^{2}}{N^{2} \rho_{0}}\left(\overline{u^{\prime} \rho^{\prime}} \frac{\partial \bar{\rho}}{\partial x}+\overline{v^{\prime} \rho^{\prime}} \frac{\partial \bar{\rho}}{\partial y}\right),
$$


and

$$
B T=-\rho_{0}\left[\overline{u^{\prime 2}} \frac{\partial \bar{u}}{\partial x}+\overline{v^{\prime 2}} \frac{\partial \bar{v}}{\partial y}+\overline{u^{\prime} v^{\prime}}\left(\frac{\partial \bar{v}}{\partial x}+\frac{\partial \bar{u}}{\partial y}\right)\right]
$$

are calculated to represent the rate of energy conversion from MPE to EPE and from MKE to EKE, where $g, \rho_{0}$ and $N^{2}$ represent acceleration due to gravity, the background density of seawater, and the square of the buoyancy frequency, respectively.

Negative $B C$ indicates that EPE is converted to MPE when the eddy density flux $\left(\overline{\mathbf{u}_{\mathbf{h}}^{\prime} \rho^{\prime}}\right)$ follows the direction of the horizontal gradient of mean density $\left(\nabla_{h} \bar{\rho}\right)$. Conversely, the MPE is converted to EPE with a positive $B C$ term if $\overline{\mathbf{u}_{\mathbf{h}}^{\prime} \rho^{\prime}}$ is against the direction of $\nabla_{h} \bar{\rho}$. Figure 2 plots the depth-integrated $B C$ term over the upper $200 \mathrm{~m}$ in winter and summer. Most of the contribution to the integrals is from the upper $200 \mathrm{~m}$ of the water column (not shown), consistent with the higher EKE contained in those layers (Figure 1). The most noticeable feature is the prevailing positive value in winter in the central and northern basins, although mingled with a few small negative patches in the northern basin. This suggests that in winter the MPE converts to EPE, which could be released and converted to EKE. In summer, the primary regions of energy conversion are significantly reduced, lying only in a few spots at approximately $22^{\circ} \mathrm{N}$ and $25-27^{\circ} \mathrm{N}$.

More details of the energy conversion from MPE to EPE become apparent upon closer examination. The eddy density flux $\overline{\rho^{\prime} v^{\prime}}$ is reported to be typically negative north of $20^{\circ} \mathrm{N}$ [von Storch et al., 2012], which is opposite to the meridional gradient of the mean density $\frac{\partial \bar{\rho}}{\partial y}$. The influence between the zonal eddy density flux $\overline{\rho^{\prime} u^{\prime}}$ and the zonal gradient of the mean density $\frac{\partial \bar{\rho}}{\partial x}$ is much less systematic. Consequently, the baroclinic term exhibits a positive signal in the central and northern Red Sea, which directs the energy conversions 
from MPE to EKE. The total conversion rate amounts to $0.66 G W$ and $0.17 G W$ in winter and summer, respectively.

Figure 3 is the same as Figure 2 but for the energy conversion from MKE to EKE term $B T$. This term contains the terms related to the horizontal gradients of the mean flow. Similar to the $B C$, the $B T$ also exhibits a higher rate in winter, yet its contribution to energy conversion is much weaker. As shown in the winter pattern in Figure 3 (a), intense patches are situated along the $200 \mathrm{~m}$ isobath on both sides of the central and northern basins, and also in the inner basin north of $24^{\circ} \mathrm{N}$, the latter of which is probably due to the shifting of the western boundary current into an eastern boundary current along the Saudi coast, as reported by Yao et al. [2014b]. Such a unique boundary intensification behavior may be attributed to the high horizontal shear of energetic flow along the steep continental slope [Sofianos and Johns, 2003; Yao et al., 2014b], which tends to favor a dominance of energy transfer from MKE to EKE. By contrast, the EKE acquired from MKE becomes smaller in the interior basin with weaker horizontal shear of the velocity. The positive (negative) values indicate that the $\mathrm{KE}$ is transferred from (to) mean flow to (from) eddies, thus, the regions of blue and red suggest that the eddies might be frequently fluxing KE back to the mean flow. Although embedded by negative signals, the $B T$ is overall positive with a total conversion rate of $0.10 \mathrm{GW}$ in winter and $0.06 \mathrm{GW}$ in summer. Overall, in the Red Sea, the eddy energy transfer is dominated by the conversion from MPE to EPE rather than by the MKE to EKE.

Typically, the energy transfer from MKE is believed to be of importance for the production of EKE for those regions characterized by an intense current of about $1 \mathrm{~m} / \mathrm{s}$ (e.g., the Labrador Sea [Eden and Böning, 2002], the Gulf of Alaska [Shore et al., 2008] and the 
western South China Sea [Yang et al., 2013]). The Red Sea has a closed basin, though a boundary current is reported, the maximum speed of about $0.3 \mathrm{~m} / \mathrm{s}$ [Yao et al., 2014b] may not be intense enough to trigger considerable instability as compared to the aforementioned regions. As expected, the model results show that the primary EKE source in the Red Sea is from EPE, rather than from MKE.

\section{Eddy Energy Budget}

A common approach to examining the EKE in a closed basin is to calculate the energy budget as proposed by Lorenz [1955] and von Storch et al. [2012]. By calculating the complete energy budget, we can identify how the EKE is generated, redistributed and dissipated, and also estimate the energy conversions between various components of the total energy. Other than EKE, budget analysis is widely used for studying different topics in the ocean, such as the budget of salinity [Bryan and Bachman, 2015], heat [Santoso et al., 2010], carbon [Key et al., 2004], etc.

\subsection{EKE Equation}

The EKE equation is derived using the simplified governing equations for an incompressible, Boussinesq, hydrostatic ocean:

$$
\begin{gathered}
\frac{D \mathbf{u}_{h}}{D t}+f \mathbf{k} \times \mathbf{u}_{h}+\frac{\nabla_{h} p}{\rho_{0}}=\frac{\mathbf{F}_{h}}{\rho_{0}}, \\
\frac{\partial p}{\partial z}=-\rho g \\
\nabla_{h} \cdot \mathbf{u}_{h}+\frac{\partial w}{\partial z}=0 .
\end{gathered}
$$

Here, the horizontal and vertical velocities, the Coriolis parameter, the gravitational acceleration, pressure, density and forcing term are denoted by $\mathbf{u}_{h}, w, f, g, p, \rho$ (reference 
value as $\left.\rho_{0}\right)$, and $\mathbf{F}_{h}$, respectively. $\mathbf{k}$ is the vertical unit vector, and $\nabla_{h}$ is the horizontal gradient operator.

As introduced by Zhai and Marshall [2013], the system can be split into time-mean and time-varying (turbulent) components. The EKE equation associated with the perturbation of mean flow is therefore derived in the form of:

$$
-\overline{\rho^{\prime} w^{\prime}} g-\frac{\partial \overline{p^{\prime} w^{\prime}}}{\partial z}-\nabla_{h} \cdot \overline{p^{\prime} \mathbf{u}_{h}^{\prime}}-\frac{\rho_{0}}{2} \nabla \cdot \overline{\left(\mathbf{u} \cdot \mathbf{u}_{h}^{\prime 2}\right)}-\rho_{0} \overline{\mathbf{u}_{h}^{\prime} \cdot\left(\mathbf{u}^{\prime} \cdot \nabla \overline{\mathbf{u}_{h}}\right)}-\rho_{0} \overline{\frac{\partial}{\partial t}} \frac{\mathbf{u}_{h}^{\prime 2}}{2}+\overline{\mathbf{u}_{h}^{\prime} \cdot \mathbf{F}_{h}^{\prime}}=0
$$

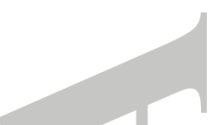

where $\mathbf{u}$ is the three-dimensional velocity. In Equation (6), the first term, $-\overline{\rho^{\prime} w^{\prime}} g$, is defined as the energy released rate from EPE to EKE and measures the strength of baroclinic production; the second term $\left(-\frac{\partial \overline{p^{\prime} w^{\prime}}}{\partial z}\right)$ and third term $\left(-\nabla_{h} \cdot \overline{p^{\prime} \mathbf{u}_{h}^{\prime}}\right)$, represent the vertical and horizontal components of pressure work; the fourth term, $-\frac{\rho_{0}}{2} \nabla \cdot \overline{\left(\mathbf{u} \cdot \mathbf{u}_{h}^{\prime 2}\right)}$, is associated with EKE flux due to advection; the fifth term, $\rho_{0} \overline{\mathbf{u}_{h}^{\prime} \cdot\left(\mathbf{u}^{\prime} \cdot \nabla \overline{\mathbf{u}_{h}}\right)}$, denotes the KE exchange between eddies and mean flow; $-\rho_{0} \frac{\bar{\partial} \frac{\mathbf{u}_{h}^{\prime 2}}{\partial t}}{2}$ represents the EKE trend; and $\overline{\mathbf{u}_{h}^{\prime} \cdot \mathbf{F}_{h}^{\prime}}$ is a term that denotes the time-varying (turbulent) external wind forcing and internal turbulent viscosity, respectively.

\subsection{Eddy Energy Sources}

The EKE sources in the Red Sea comprise the conversion from EPE, the transfer from MKE, and direct generation of EKE from time-varying (turbulent) wind stress.

Figure 5 shows the distribution of the baroclinic production term $\left(-\overline{\rho^{\prime} w^{\prime}} g\right)$ integrated in the upper $200 \mathrm{~m}$ in winter (a) and summer (b). As the definition implies, positive values of $-\overline{\rho^{\prime} w^{\prime}} g$ indicate denser water masses associated with downward movements or lighter water masses associated with upward movements. It is important to notice the difference 
between the aforementioned $B C$ and $-\overline{\rho^{\prime} w^{\prime}} g$. The $B C$ measures the energy conversion rate between the $\mathrm{MPE}$ and $\mathrm{EPE}$, while $-\overline{\rho^{\prime} w^{\prime}} g$ here represents the rate of energy conversion between EPE and EKE. Both of these terms describe the energy conversion associated with baroclinic instability but for different stages [Shore et al., 2008; Zhai and Marshall, 2013]. In Figure 5 (a), the ubiquitous positive $-\overline{\rho^{\prime} w^{\prime}} g$ in the central and northern Red Sea basins suggests that, as a source term, the baroclinicity prevails in winter by a relatively rapidly converting from EPE to EKE, where the highest rate exceeds $5 \times 10^{-3} \mathrm{Wm}^{-2}$. Compared to the intense strength of baroclinic production in winter, the signal in summer (Figure $5(\mathrm{~b})$ ) is much weaker. In addition, the vertical profile of $-\overline{\rho^{\prime} w^{\prime}} g$ along the Red Sea axis (Figure 5 (c) (d)) reveals that the vast majority of values, if not all, are positive. This release of EPE is mainly found in the upper layers, which is stringently confined to less than $50 \mathrm{~m}$ in summer but deepens to over $200 \mathrm{~m}$ in winter, and is particularly more intense in the northern basin between $24^{\circ} \mathrm{N}$ and $26^{\circ} \mathrm{N}$ where EKE reaches its maximum. As an estimate, the total energy conversion from EPE to EKE in the Red Sea is about $0.64 G W$ in winter and $0.11 G W$ in summer.

As a reservoir of EKE, the EPE is not only transferred from MPE (through the term $B C$ as discussed in section 3.2), but also generated due to time-varying fluxes of heat and freshwater on the surface. According to von Storch et al. [2012], the generation of EPE can be estimated by

$$
G_{E P E}=\frac{g^{2}}{N^{2} \rho_{0}}\left(\alpha_{s} \overline{\rho_{s}^{\prime} J_{s}^{\prime}}+\beta_{s} \overline{\rho_{s}^{\prime} G_{s}^{\prime}}\right)
$$

where $\alpha_{s}$ and $\beta_{s}$ are values of expansion coefficients in the surface layer. $J_{s}=\left(1 / \rho_{s} c\right) H$ denotes the surface temperature flux and $G_{s}=S_{s}(E-P)$ represents the surface salinity flux. $\rho_{s}, S_{s}$ are the density and salinity of surface seawater, and $c$ the specific heat of 
seawater. $H$ and $E-P$ indicate the net heat flux and net freshwater flux, respectively. The distribution of winter and summer $G_{E P E}$ is shown in Figure 4. In winter, the EPE is likely to be generated in the central Red Sea between $17^{\circ} \mathrm{N}$ and $22^{\circ} \mathrm{N}$, as well as in the northern basin along the coast of Saudi Arabia. In summer, however, this term fades away and even becomes negative in the northern Red Sea, implying a net loss of EPE in that region due to surface buoyancy flux. The direct generation of EPE is fairly small compared to that converted from MPE, with only $0.09 G W$ in winter and $-0.02 G W$ in summer. (It should be noted that the color scale used in Figure 4 is different from those in other figures in this paper.)

Another source of EKE is represented by $\rho_{0} \overline{\mathbf{u}_{h}^{\prime} \cdot\left(\mathbf{u}^{\prime} \cdot \nabla \overline{\mathbf{u}_{h}}\right)}$, the transfer from MKE through Reyholds stresses [Orlanski and Cox, 1973]. This term is essentially equal to $B T+\left(-\overline{u^{\prime} w^{\prime}} \frac{\partial \bar{u}}{\partial z}-\overline{v^{\prime} w^{\prime}} \frac{\partial \bar{v}}{\partial z}\right)$, the latter of which represents the energy transfer due to vertical shear instabilities [Xie et al., 2007]. This term is fairly small (not shown, with a net conversion rate of $-0.02 G W$ in winter and $-0.001 G W$ in summer) compared to the $B T$, and consequently, the distribution of $\rho_{0} \overline{\mathbf{u}_{h}^{\prime} \cdot\left(\mathbf{u}^{\prime} \cdot \nabla \overline{\mathbf{u}_{h}}\right)}$ conforms with that of $B T$ in section 3.2. As previously stated, the energy transferred from MKE contributes only a small portion of EKE.

The last term, $\overline{\mathbf{u}_{h}^{\prime} \cdot \mathbf{F}_{h}^{\prime}}$, includes the direct generation of EKE due to the time-varying (turbulent) wind stress. Wind power input transfers the atmospheric kinetic energy into the ocean. The mean wind power input can be calculated with $\Omega=\overline{\tau_{x} u_{s}}+\overline{\tau_{y} v_{s}}[$ Zhai et al., 2012; Huang et al., 2006], where $\tau_{x}, \tau_{y}$ are the surface wind stress and $u_{s}, v_{s}$ are the surface current velocity. Furthermore, this term can be split into $\Omega_{1}=\overline{\tau_{x}} \cdot \overline{u_{s}}+\overline{\tau_{y}} \cdot \overline{v_{s}}$ and $\Omega_{2}=\overline{\tau_{x}^{\prime} u_{s}^{\prime}}+\overline{\tau_{y}^{\prime} v_{s}^{\prime}}$, representing the generation rates of MKE and EKE from wind 
energy, where $\tau$ and $\tau^{\prime}$ denote the mean and time-varying (turbulent) component of wind stress, respectively. Figure 6 shows the distribution of $\Omega_{2}$ in winter (a) and in summer (b). The major contribution of energy input through turbulent wind occurs in winter over the southern Red Sea. The intensified signal suggests that the time-varying current velocity over that region is, on average, oriented along the same direction as the timevarying wind stress. Nevertheless, a fairly weak evidence exists supporting a high EKE in this region (Figure 1 (c)). Therefore, one may reasonably infer that the energy gained from time-varying wind stress is rapidly dissipated or propagated to other areas. In the northern basin, turbulent wind unexpectedly diminishes, negligibly influencing on the EKE. The total power input from time-varying wind fields is $0.31 G W$ in winter and $0.13 G W$ in summer. Some well-know wind-driven eddies, for example, the dipole eddies formed by the Tokar wind jet near $19^{\circ} N$ in August [Zhai and Marshall, 2013], do not appear in Figure 6. This was expected because, as the perturbations of the monthly mean current of climatology, eddies with a quasi-stationary feature (e.g., the anticyclonic eddy between $23^{\circ} \mathrm{N}$ and $24^{\circ} \mathrm{N}$ [Sofianos and Johns, 2003; Quadfasel and Baudner, 1993]) or those appearing in a certain month (e.g., the Tokar-originated dipole eddies) are ruled out and, therefore, not included in this calculation.

The sixth term on the left-hand side of Equation (6), $-\rho_{0} \frac{\partial \frac{\mathbf{u}_{h}^{\prime 2}}{\partial t}}{2}$, represents the tendency of EKE. This term is not significant within the season (not shown), with a increase of $0.02 G W$ in winter and a decrease of $0.02 G W$ in summer.

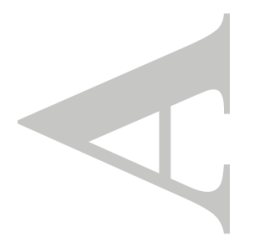




\subsection{Eddy Energy Redistributions and Sink}

As indicated in Equation (6), the EKE can be redistributed by the vertical pressure work term $-\frac{\partial p^{\prime} w^{\prime}}{\partial z}$, the horizontal pressure work term $-\nabla_{h} \cdot \overline{p^{\prime} \mathbf{u}_{h}^{\prime}}$, and the advection term $-\frac{\rho_{0}}{2} \nabla \cdot \overline{\left(\mathbf{u} \cdot \mathbf{u}_{h}^{\prime 2}\right)}$

The depth-integrated vertical pressure work term is shown Figure 7 in winter (a) and summer (b). An integration of $-\frac{\partial \overline{p^{\prime} w^{\prime}}}{\partial z}$ in depth is equivalent to $-\left.\left.\overline{p^{\prime} w^{\prime}}\right|_{-h} ^{0} \approx \overline{p^{\prime} w^{\prime}}\right|_{-h}$ (the $w^{\prime}$ on the surface is approximately zero), which is noted as the vertical eddy energy flux [Zhai and Marshall, 2013], representing the redistribution of eddy energy in the vertical. The signal is mixed but, on average, prevalently negative. The overwhelming blue patches in Figure 7 (a) suggest that the eddy energy flux is predominately downward in the central and northern interior basins, and increasingly rises towards the offshore of Saudi Arabia while a narrow band of upward vertical energy flux is found along the Egyptian coast.

As a close-up representation, profiles of winter $\overline{p^{\prime} w^{\prime}}$ along three cross-sections are illustrated in Figure 7 (c) - (e) to better present the redistribution of eddy energy in the vertical. Figure 7 (c) shows the $\overline{p^{\prime} w^{\prime}}$ along the main axis of the Red Sea. In the northern basin, weak upward energy flux is found near the surface while deeper down below about $50 \mathrm{~m}$, it is dominated by a downward energy flux. The overall downward pattern of energy flux, as shown in Figure 7 (c), is consistent with the fact that sources of eddy energy in the northern basin are located in the upper ocean. This feature is even more abundantly visible as the darker blue patches along the Saudi coast, as shown in Figure 7 (e). On the western side (Figure $7(\mathrm{~d})$ ), however, a very narrow band of upward eddy energy flux appears along the Egyptian coast, possibly associated with the winter upwelling as reported by Yao et al. [2014b]. Near the sloping bottom topography along either the west 
or the east coast, the vertical eddy energy flux exhibits a complex structure, probably associated with the interactions between the flow and the topography. Overall, the EKE propagates downward with a rate of $0.09 G W$ in winter and $0.01 G W$ in summer.

Since the vertical component of advection term is quite small (not shown), the term $-\frac{\rho_{0}}{2} \nabla \cdot \overline{\left(\mathbf{u} \cdot \mathbf{u}_{h}^{\prime 2}\right)}$ reduces to $-\frac{\rho_{0}}{2} \nabla \cdot \overline{\left(\mathbf{u}_{\mathbf{h}} \cdot \mathbf{u}_{h}^{\prime 2}\right)}$. Therefore, we treat the advection term and the horizontal pressure work term $-\nabla_{h} \cdot \overline{p^{\prime} \mathbf{u}_{h}^{\prime}}$ as a single entity, to reflect the horizontal eddy energy flux [Xie et al., 2007], which was plotted in Figure 8 for the distribution in winter (a) and summer (b). Similar to $-\overline{\rho^{\prime} w^{\prime}} g$ and $-\frac{\partial \overline{p^{\prime} w^{\prime}}}{\partial z}$, the horizontal eddy energy flux also intensifies in winter. In the interior basin, this term reveals a mix of positive and negative values, suggesting that eddy energy is actively involved in horizontal advection and exchange. In addition, a prominent feature appears as a series of negative signals lying throughout the southern basin along the $200 \mathrm{~m}$ isobath on the west, which marks a significant horizontal divergence of energy. Since there is very limited energy from EPE and MKE in the southern Red Sea (Figure $5(\mathrm{a})$ ), the energy source in this region is, therefore, inferred to originate from the turbulent wind stress (Figure 6 (a)). In winter, not only is there a more notable horizontal distribution, but the vertical structure of $-\left(\nabla_{h} \cdot \overline{p^{\prime} \mathbf{u}_{h}^{\prime}}+\frac{\rho_{0}}{2} \nabla \cdot \overline{\left(\mathbf{u} \cdot \mathbf{u}_{h}^{\prime 2}\right)}\right)$ also deepens in the central and northern basins (Figure 8 (c)). In winter, the horizontal eddy energy flux could reach more than $200 \mathrm{~m}$ and deplete the EKE at a rate of $0.21 G W$, whereas, in summer it is mainly restricted to upper layers near the surface at EKE decreases at a rate of $0.08 \mathrm{GW}$. In both seasons, the deep waters remain fairly quiescent.

It is important to point that the pressure work term and the advection term serve to redistribute the eddy component of pressure work and the EKE in the basin. Both 
terms are defined in a divergent form, so that the integration of either term over the whole volume should be approximately balanced out under a rigid lid approach [Hecht and Hasumi, 2013]. In our calculation, however, nonzero values are obtained primarily because these terms are only integrated in the upper $200 \mathrm{~m}$ waterbody, and not over the whole volume. The negative net fluxes reveal that EKE propagates into deep ocean and more significantly, into coastal (shallower) regions.

Any remaining EKE is either transferred into sub-mesoscale motions or dissipated by turbulent processes associated with dissipation and its divergence/convergence [Wunsch and Ferrari, 2004], which here are merged as a single entity to represent the sink of EKE. The sink term is found ubiquitously throughout the Red Sea (Figure 9), particularly in the central and northern basins, and appears as prominent negative signals that intensify towards the north. In winter, net dissipation amounts to $0.73 G W$, compared with 0.23 $G W$ in summer.

\section{Discussion and Summary}

Based on a high-resolution MITgcm, we investigated the budget of eddy energy sources, redistribution and sink in the Red Sea during different seasons. In the Red Sea, overturning circulation has been reported to exhibit a distinct seasonally reversing pattern [Yao et al.,2014a, b; Sofianos and Johns, 2003; Zhai, 2014], consequently, eddies are calculated with regards to a climatologically monthly mean of flow to eliminate the seasonally varying signals. Our results agree with Zhan et al. [2014] who found that eddy activity has a significant seasonality that peaks in winter and troughs in summer. The highest EKE is found in the central and northern Red Sea basins during both seasons with a surface intensification. The main EKE strength is stored in the upper $200 \mathrm{~m}$, similar to that in 
the South China Sea [Yang et al., 2013], yet shallower compared to the the North Atlantic [Zhai and Marshall, 2013].

As an indicator of energy transfer between MKE and EKE, the BT term measures the production of EKE associated with mean flow shear. This term appears mainly along the eastern and western boundaries of the basin. $B C$ represents the baroclinic terms related to the energy conversion between MPE and EPE, the primary regions of which cover almost the entire basin with a predominately positive signal, indicating a conversion from MPE to EPE. The averaged positive values of both the $B T$ and $B C$ suggest that the eddies tap both the kinetic and available potential energy reservoirs of the mean state. In addition, both terms prevail in winter, when the total rate of energy conversion is about four times larger than that in summer.

A further analysis of the budget of sources, redistributions and sink of EKE in the Red Sea is conducted. The conversion between EPE and EKE, $-\overline{\rho^{\prime} w^{\prime}} g$, is the primary source of EKE in the central and northern Red Sea with a subsurface intensification. As reported by Papadopoulos et al. [2012], the winter heat flux has a great influence on the eddies and sinking of upper layer water in the northern Red Sea. We extend this by finding a good correlation between the distribution of $-\overline{\rho^{\prime} w^{\prime}} g$ and the net heat flux (Figure 10). This occurs because in winter, as shown by the red patches over the central and particularly northern basins (Figure 10 (a)), when considerable heat loss leads to cooling in the upper layers, the cooled surface water becomes denser, deepening the isopycnal (not shown). Note that the central and northern basins are subjected to a northward gradient of heat loss, as a result, the isopycnal is tilted to the north (shallower in the south and deeper in the north). Different from the tilting of isopycnals in other oceans mainly caused by 
the Ekman pumping effect [Yang et al., 2013; Zhai and Marshall, 2013], the along-basin isopycnal tilt in the Red Sea is a consequence of the meridional gradient of net heat flux. The tilted isopycnal in the central and northern basins generates available potential energy, which, when accompanied with a relatively smaller Richardson number in winter, is likely to be released by triggering baroclinic instability that subsequently form eddies [Zhan et al., 2014]. Eddies generated by such baroclinic instability can balance surface buoyancy loss in a marginal sea [Visbeck et al., 1996; Marshall and Schott, 1999], and, therefore, have a considerable effect on the buoyancy-driven circulation in the Red Sea [Zhai, 2014]. In contrast, in summer the entire basin is subjected to a positive net heat flux. The upper level of sea water is heated and remains stratified. As a result, strong stratification is more likely to limit eddy activities and lead to reduced EKE.

Other sources of EKE include direct power input from the time-verying wind $\left(\overline{\tau_{x}^{\prime} u_{s}^{\prime}}+\overline{\tau_{y}^{\prime} v_{s}^{\prime}}\right.$, mainly found in the southern basin) and that transferred from MKE (mainly along both sides of the boundaries). Although the net contribution of EKE from MKE is relatively small, the positive patterns embedded with negative signals suggest a rapid energy exchange between mean flow and eddies. The EKE is redistributed by the divergence of energy in both vertical and horizontal directions. Vertically, the EKE in the upper layers is propagated to deeper ocean via a negative $\overline{p^{\prime} w^{\prime}}$ in most of the basin except for a narrow band of upward flux near the Egyptian coast in the northern basin. The vertical EKE fluxes may result from mismatches between the depth at which EKE is generated or converted, and the horizontal eddy energy fluxes that disperse the energy [Zhai and Marshall, 2013]. Horizontally, as represented by $-\left(\nabla_{h} \cdot \overline{p^{\prime} \mathbf{u}_{h}^{\prime}}+\frac{\rho_{0}}{2} \nabla \cdot \overline{\left(\mathbf{u} \cdot \mathbf{u}_{h}^{\prime 2}\right)}\right)$, the eddies may rapidly transfer the EKE from the eddying region to the adjacent background water 
mass. These overall negative value of integrated horizontal pressure work term and advection term suggest that EKE is propagated from the inner basin into the coastal regions. The EKE is balanced ubiquitously in the basin by the turbulent dissipation processes or by transfer to sub-mesoscale motions.

Because the climatology-based definition of an eddy does not include quasi-stationary eddies or those recurrent eddies appearing in a certain month, a detailed understanding of how these eddies are generated requires case-by-case studies. In addition, we have not discussed the details of dissipation processes, nor have we approached the mechanisms of energy conversion to sub-mesoscale and small-scale dynamics, especially in shallow areas, which might be different and more complex. More work is required in the future to understand the role of each factor in the energy balance. This study is a step toward understanding the processes modulating eddies' variability in the Red Sea.

\section{Acknowledgments.}

The research reported in this manuscript was supported by King Abdullah University of Science and Technology (KAUST) and made use of the resources of the Supercomputing Laboratory and computer clusters at KAUST. The data used in this study may be obtained from the authors upon request (ibrahim.hoteit@kaust.edu.sa).

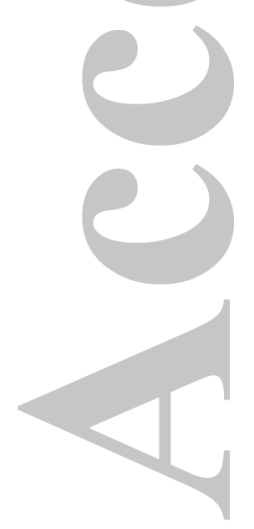




\section{References}

Bower, A., and J. Farrar (2015), Air-Sea Interaction and Horizontal Circulation in the Red Sea, in The Red Sea SE - 19, edited by N. M. A. Rasul and I. C. F. Stewart, Springer Earth System Sciences, pp. 329-342, Springer Berlin Heidelberg, doi:10.1007/978-3-66245201-1_19.

Bryan, F., and S. Bachman (2015), Isohaline Salinity Budget of the North Atlantic Salinity Maximum, Journal of Physical Oceanography, 45(3), 724-736, doi:10.1175/JPO-D-140172.1.

Chen, C., R. Li, L. Pratt, R. Limeburner, R. C. Beardsley, A. Bower, H. Jiang, Y. Abualnaja, Q. Xu, H. Lin, X. Liu, J. Lan, and T. Kim (2014), Process modeling studies of physical mechanisms of the formation of an anticyclonic eddy in the central Red Sea, Journal of Geophysical Research: Oceans, 119(2), 1445-1464, doi: 10.1002/2013JC009351.

Clifford, M., C. Horton, J. Schmitz, and L. H. Kantha (1997), An oceanographic nowcast/forecast system for the Red Sea, Journal of Geophysical Research-Oceans, 102(C11), 25,101-25,122, doi:Doi 10.1029/97jc01919.

Ducet, N., P. Y. Le Traon, and G. Reverdin (2000), Global high-resolution mapping of ocean circulation from TOPEX/Poseidon and ERS-1 and-2, Journal of Geophysical Research-Oceans, 105(C8), 19,477-19,498, doi:Doi 10.1029/2000jc900063.

Eden, C., and C. Böning (2002), Sources of Eddy Kinetic Energy in the Labrador Sea, doi:10.1175/1520-0485(2002)032ز3346:SOEKEI¿2.0.CO;2.

Edwards, F. J. (1987), Red Sea. -(Key environments), first ed., 61 pp., Pergamon Press, Exeter. 
Eshel, G., and N. H. Naik (1997), Climatological coastal jet collision, intermediate water formation, and the general circulation of the Red Sea, Journal of Physical Oceanography, 27(7), 1233-1257, doi:Doi 10.1175/1520-0485(1997)027;1233:Ccjciw¿2.0.Co;2.

Ferrari, R., and C. Wunsch (2009), Ocean circulation kinetic energy: reservoirs, sources, and sinks, Tech. rep., doi:10.1146/annurev.fluid.40.111406.102139.

Gerges, M. A. (2002), The Red Sea and Gulf of Aden Action Plan-Facing the challenges of an ocean gateway, Ocean $\mathscr{G}$ Coastal Management, 45(11-12), 885-903, doi: 10.1016/S0964-5691(02)00112-6.

Hecht, M. W., and H. Hasumi (2013), Ocean Modeling in an Eddying Regime, 1-409 pp., doi:10.1029/GM177.

Huang, R. X., W. Wang, and L. L. Liu (2006), Decadal variability of wind-energy input to the world ocean, in Deep-Sea Research Part II: Topical Studies in Oceanography, vol. 53, pp. 31-41, doi:10.1016/j.dsr2.2005.11.001.

Jiang, H. S., T. Farrar, R. C. Beardsley, R. Chen, and C. S. Chen (2009), Zonal surface wind jets across the Red Sea due to mountain gap forcing along both sides of the Red Sea, Geophysical Research Letters, 36, doi:Artn L19605 Doi 10.1029/2009gl040008.

Key, R. M., A. Kozyr, C. L. Sabine, K. Lee, R. Wanninkhof, J. L. Bullister, R. A. Feely, F. J. Millero, C. Mordy, and T. H. Peng (2004), A global ocean carbon climatology: Results from Global Data Analysis Project (GLODAP), Global Biogeochemical Cycles, 18(4), 1-23, doi:10.1029/2004GB002247.

Köhl, A., and D. Stammer (2008), Variability of the Meridional Overturning in the North Atlantic from the 50-Year GECCO State Estimation, Journal of Physical Oceanography, 38(9), 1913-1930, doi:10.1175/2008JPO3775.1. 
Le Traon, P. Y., and G. Dibarboure (1999), Mesoscale Mapping Capabilities of MultipleSatellite Altimeter Missions, Journal of Atmospheric and Oceanic Technology, 16(9), 1208-1223, doi:10.1175/1520-0426(1999)016¡1208:MMCOMS¿2.0.CO;2.

Lorenz, E. N. (1955), Available potential energy and the maintenance of the general circulation, doi:10.3402/tellusa.v7i2.8796.

Marshall, J., and F. Schott (1999), Open-ocean convection: Observations, theory, and models, Reviews of Geophysics, 37(1), 1-64, doi:10.1029/98RG02739.

Marshall, J., C. Hill, L. Perelman, and A. Adcroft (1997), Hydrostatic, quasi-hydrostatic, and nonhydrostatic ocean modeling, Journal of Geophysical Research, 102(C3), 5733, doi:10.1029/96JC02776.

Olbers, D., J. Willebrand, and C. Eden (2012), Ocean Dynamics, Springer Verlag Berlin, Berlin.

Orlanski, I., and M. D. Cox (1973), Baroclinic Instability in Ocean Currents, Geophys. Fluid Dyn., 4, 297-332.

Papadopoulos, V. P., P. Zhan, S. S. Sofianos, D. E. Raitsos, M. Qurban, Y. Abualnaja, A. Bower, H. Kontoyiannis, A. Pavlidou, M. Asharaf T.T., N. Zarokanellos, and I. Hoteit (), Factors governing the deep ventilation of the Red Sea, Journal of Geophysical Research: Oceans, 201(5), doi:10.1002/2015JC010996.

Papadopoulos, V. P., Y. Abualnaja, S. A. Josey, A. Bower, D. E. Raitsos, H. Kontoyiannis, and I. Hoteit (2012), Atmospheric Forcing of the Winter Air-Sea Heat Fluxes over the Northern Red Sea, Journal of Climate, 26(5), 1685-1701, doi:10.1175/JCLI-D-1200267.1 
Pedlosky, J. (1992), Geophysical Fluid Dynamics, Springer study edition, Springer New York.

Quadfasel, D., and H. Baudner (1993), Gyre-scale circulation cells in the Red-Sea, Oceanologica Acta, $16(197$ 4), 221-229.

Rasul, N. M. A., and I. C. F. Stewart (2015), The Red Sea: The Formation, Morphology, Oceanography and Environment of a Young Ocean Basin, Springer.

Richardson, P. L. (1983), Eddy kinetic energy in the North Atlantic from surface drifters, Journal of Geophysical Research, 88, 4355, doi:10.1029/JC088iC07p04355.

Santoso, A., A. Sen Gupta, and M. H. England (2010), Genesis of Indian Ocean mixed layer temperature anomalies: A heat budget analysis, Journal of Climate, 23(20), 53755403, doi:10.1175/2010JCLI3072.1.

Shore, J., M. W. Stacey, and D. G. Wright (2008), Sources of eddy energy simulated by a model of the northeast Pacific Ocean, Journal of Physical Oceanography, 38(10), 2283-2293, doi:10.1175/2008JPO3800.1.

Sofianos, S., and W. E. Johns (2015), Water Mass Formation, Overturning Circulation, and the Exchange of the Red Sea with the Adjacent Basins.

Sofianos, S. S., and W. E. Johns (2003), An Oceanic General Circulation Model (OGCM) investigation of the Red Sea circulation: 2. Three-dimensional circulation in the Red Sea, Journal of Geophysical Research-Oceans, 108(C3), doi:Artn 3066 Doi 10.1029/2001jc001185.

Sofianos, S. S., and W. E. Johns (2007), Observations of the summer Red Sea circulation, Journal of Geophysical Research-Oceans, 112(C6), doi:10.1029/2006jc003886. 
Stramma, L., H. W. Bange, R. Czeschel, A. Lorenzo, and M. Frank (2013), On the role of mesoscale eddies for the biological productivity and biogeochemistry in the eastern tropical Pacific Ocean off Peru, Biogeosciences, 10(11), 7293-7306, doi:10.5194/bg-10$7293-2013$.

Tragou, E., and C. Garrett (1997), The shallow thermohaline circulation of the Red Sea, Deep-Sea Research Part I: Oceanographic Research Papers, 44(8), 1355-1376, doi: 10.1016/S0967-0637(97)00026-5.

Vallis, G. K. (2006), Atmospheric and oceanic fluid dynamics: fundamentals and largescale circulation, 745 pp., Cambridge University Press, Cambridge.

Visbeck, M., J. Marshall, and H. Jones (1996), Dynamics of Isolated Convective Regions in the Ocean, Journal of Physical Oceanography, 26(9), 1721-1734, doi:10.1175/15200485(1996)026¡1721:DOICRI ¿2.0.CO;2.

von Storch, J.-S., C. Eden, I. Fast, H. Haak, D. Hernández-Deckers, E. Maier-Reimer, J. Marotzke, and D. Stammer (2012), An Estimate of the Lorenz Energy Cycle for the World Ocean Based on the STORM/NCEP Simulation, Journal of Physical Oceanography, 42(12), 2185-2205, doi:10.1175/JPO-D-12-079.1.

Werner, F., and K. Lange (1975), A bathymetric survey of the Sill Area between the Red Sea and the Gulf of Aden, D], Schweizerbart.

Wunsch, C., and R. Ferrari (2004), VERTICAL MIXING, ENERGY, AND THE GENERAL CIRCULATION OF THE OCEANS, Annual Review of Fluid Mechanics, 36(1), 281-314, doi:10.1146/annurev.fluid.36.050802.122121.

Xie, L., X. Liu, and L. J. Pietrafesa (2007), Effect of Bathymetric Curvature on Gulf Stream Instability in the Vicinity of the Charleston Bump, Journal of Physical Oceanog- 
raphy, $37(3)$, 452-475, doi:10.1175/JPO2995.1.

Xiu, P., and F. Chai (2011), Modeled biogeochemical responses to mesoscale eddies in the South China Sea, Journal of Geophysical Research: Oceans, 116(10), doi: 10.1029/2010JC006800.

Yang, H., L. Wu, H. Liu, and Y. Yu (2013), Eddy energy sources and sinks in the South China Sea, Journal of Geophysical Research: Oceans, 118(9), 4716-4726, doi: 10.1002/jgrc.20343.

Yao, F., I. Hoteit, L. J. Pratt, A. S. Bower, P. Zhai, A. Köhl, and G. Gopalakrishnan (2014a), Seasonal overturning circulation in the Red Sea: 1. Model validation and summer circulation, Journal of Geophysical Research: Oceans, pp. 2238-2262, doi: 10.1002/2013JC009004.

Yao, F., I. Hoteit, L. J. Pratt, A. S. Bower, A. Köhl, G. Gopalakrishnan, and D. Rivas (2014b), Seasonal overturning circulation in the Red Sea. 2: Winter circulation, Journal of Geophysical Research: Oceans, pp. 2263-2289, doi:10.1002/2013JC009331.

Zhai, P. (2014), Buoyancy-driven circulation in the Red Sea, Ph.D. thesis, Massachusetts Institute of Technology and Woods Hole Oceanographic Institution, Woods Hole, MA, doi:10.1575/1912/6752.

Zhai, P., and A. Bower (2013), The response of the Red Sea to a strong wind jet near the Tokar Gap in summer, Journal of Geophysical Research: Oceans, 118(1), 421-434, doi:10,1029/2012JC008444.

Zhai, X., and D. P. Marshall (2013), Vertical eddy energy fluxes in the North Atlantic subtropical and subpolar gyres, Journal of Physical Oceanography, 43(1), 95-103, doi: 10.1175/JPO-D-12-021.1. 
Zhai, X., H. L. Johnson, and D. P. Marshall (2010), Significant sink of ocean-eddy energy near western boundaries, Nature Geosci, 3(9), 608-612.

Zhai, X., H. L. Johnson, D. P. Marshall, and C. Wunsch (2012), On the wind power input to the ocean general circulation, doi:10.1175/JPO-D-12-09.1.

Zhan, P., A. C. Subramanian, F. Yao, and I. Hoteit (2014), Eddies in the Red Sea: A statistical and dynamical study, Journal of Geophysical Research: Oceans, 119(6), 3909-3925, doi:10.1002/2013JC009563.
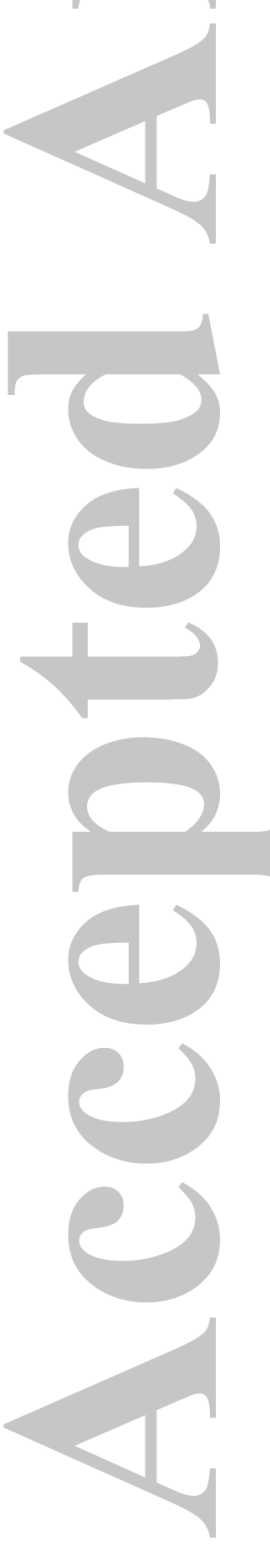

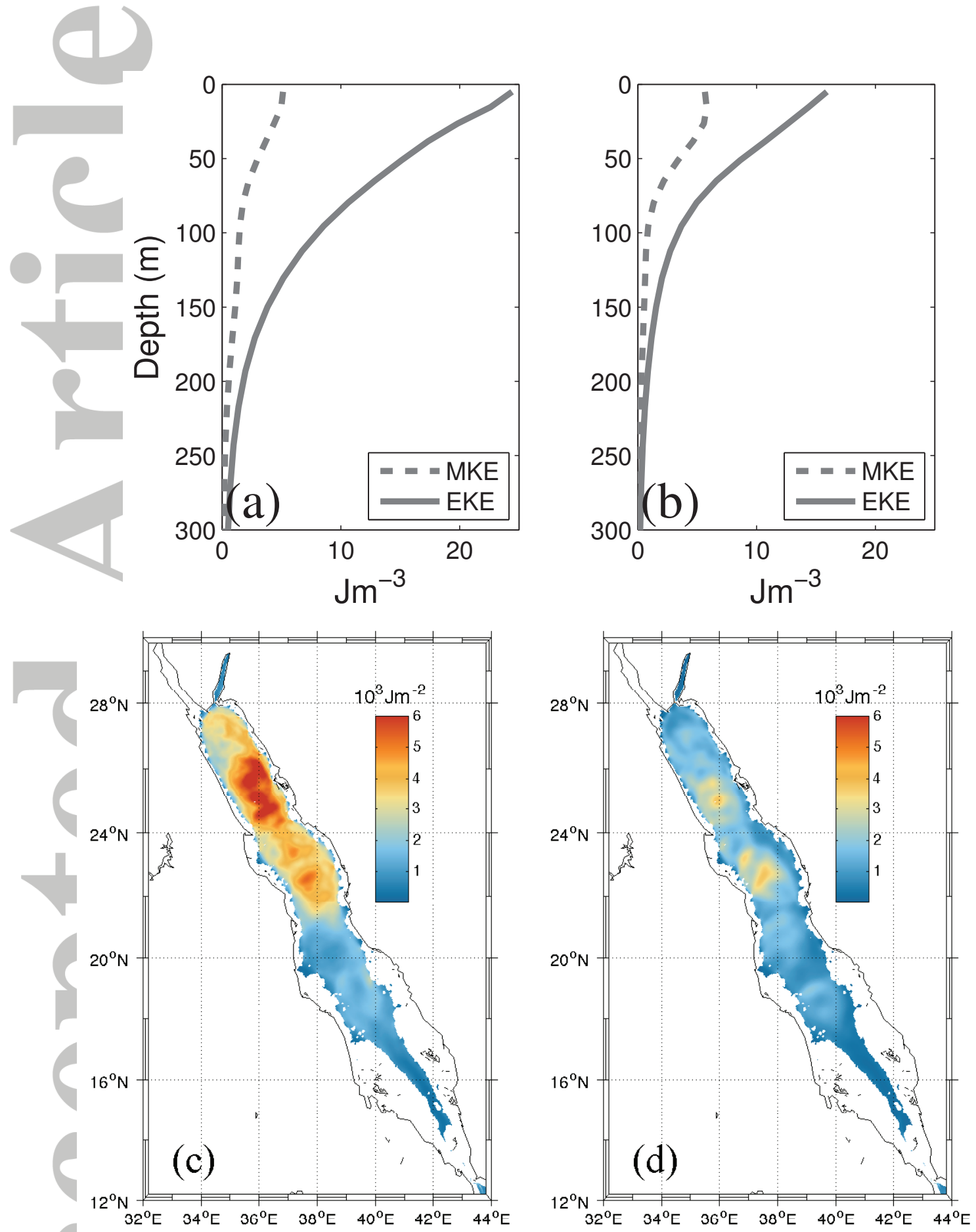

Figure 1. Basin-averaged (between $14.5^{\circ} \mathrm{N}$ and $28^{\circ} \mathrm{N}$ ) vertical profiles of the EKE and MKE in the central and northern Red Sea in (a) winter (Jan, Feb and Mar) and (b) summer (Jul, Aug and Sep), and the mean EKE integrated in the upper $200 m$ in (c) winter and (d) summer. 

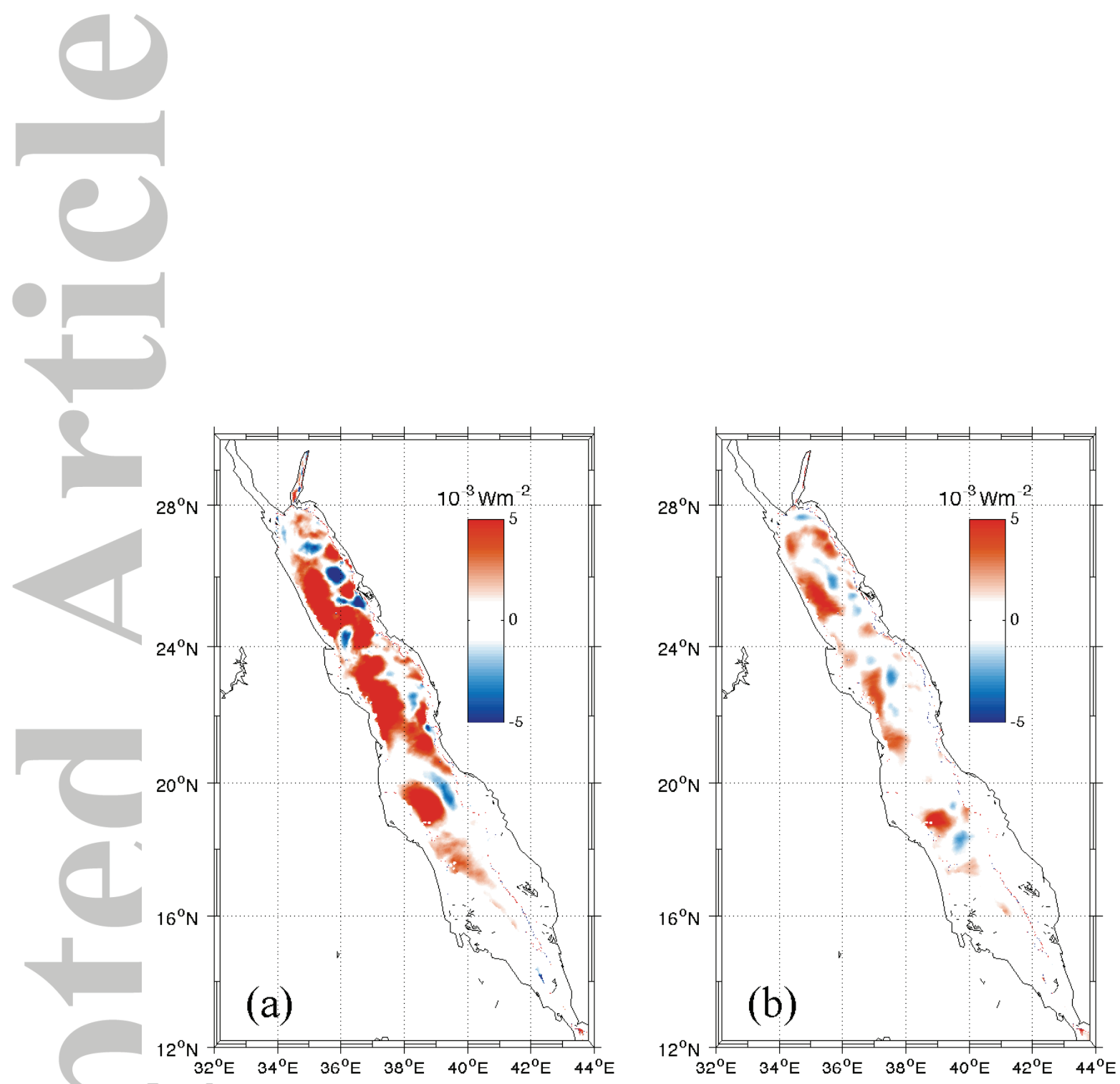

Figure 2. Distribution of the MPE-to-EPE term, $B C\left(-\frac{g^{2}}{N^{2} \rho_{0}}\left(\overline{u^{\prime} \rho^{\prime}} \frac{\partial \bar{\rho}}{\partial x}+\overline{v^{\prime} \rho^{\prime}} \frac{\partial \bar{\rho}}{\partial y}\right)\right)$, integrated in the upper $200 \mathrm{~m}$ in (a) winter and (b) summer.

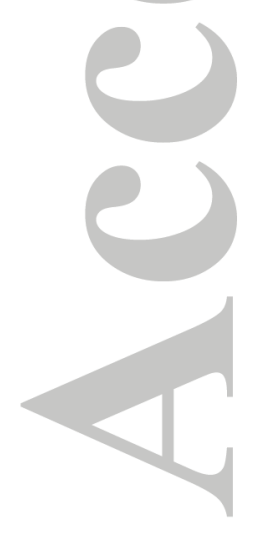



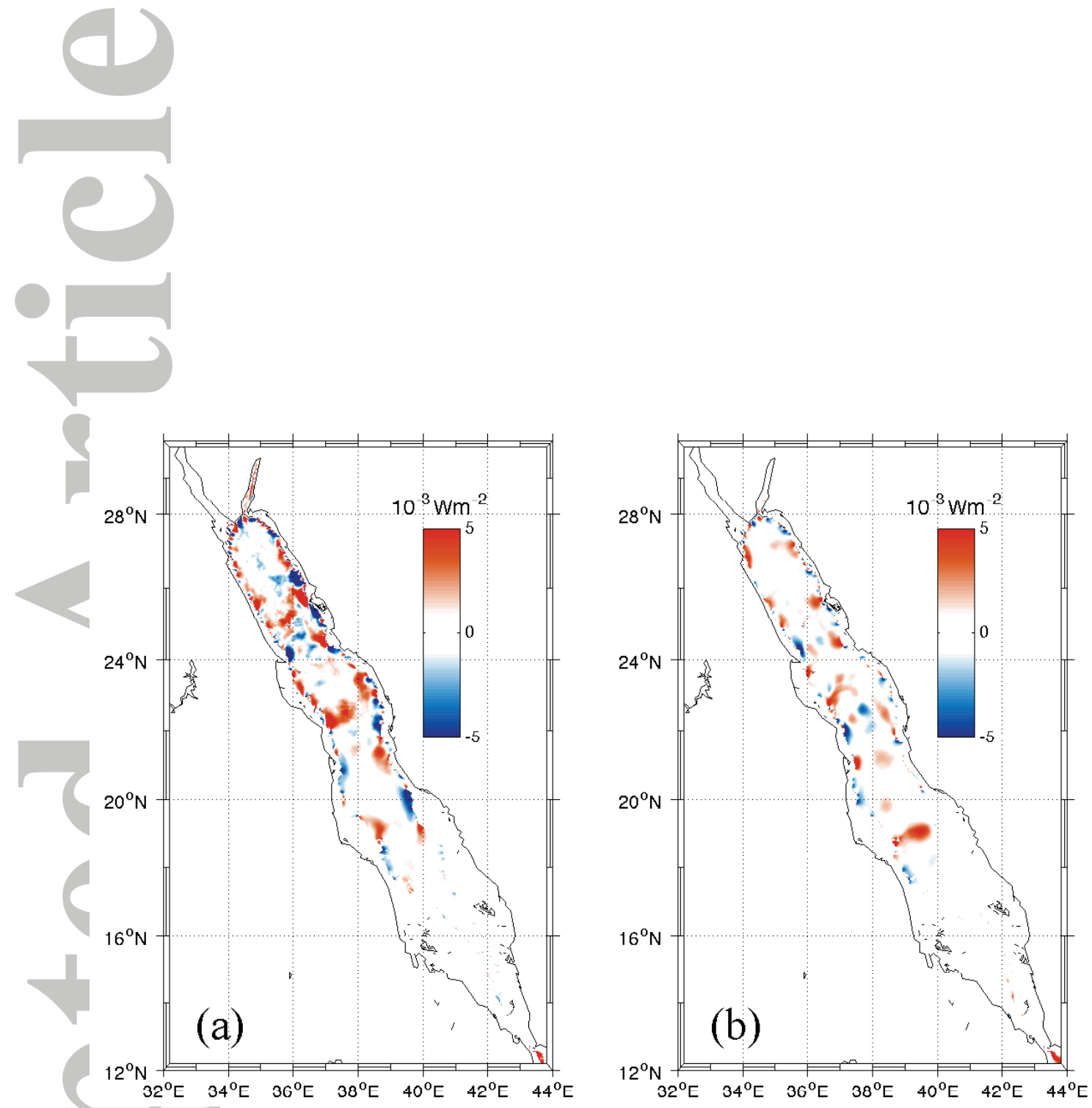

Figure 3. Distribution of the MKE-to-EKE term, $B T\left(-\rho_{0}\left[\overline{u^{\prime 2}} \frac{\partial \bar{u}}{\partial x}+\overline{v^{\prime 2}} \frac{\partial \bar{v}}{\partial y}+\overline{u^{\prime} v^{\prime}}\left(\frac{\partial \bar{v}}{\partial x}+\frac{\partial \bar{u}}{\partial y}\right)\right]\right)$, integrated in the upper $200 \mathrm{~m}$ in (a) winter and (b) summer.

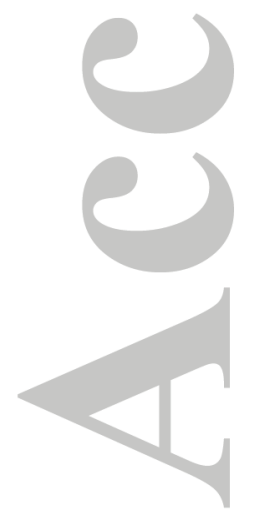



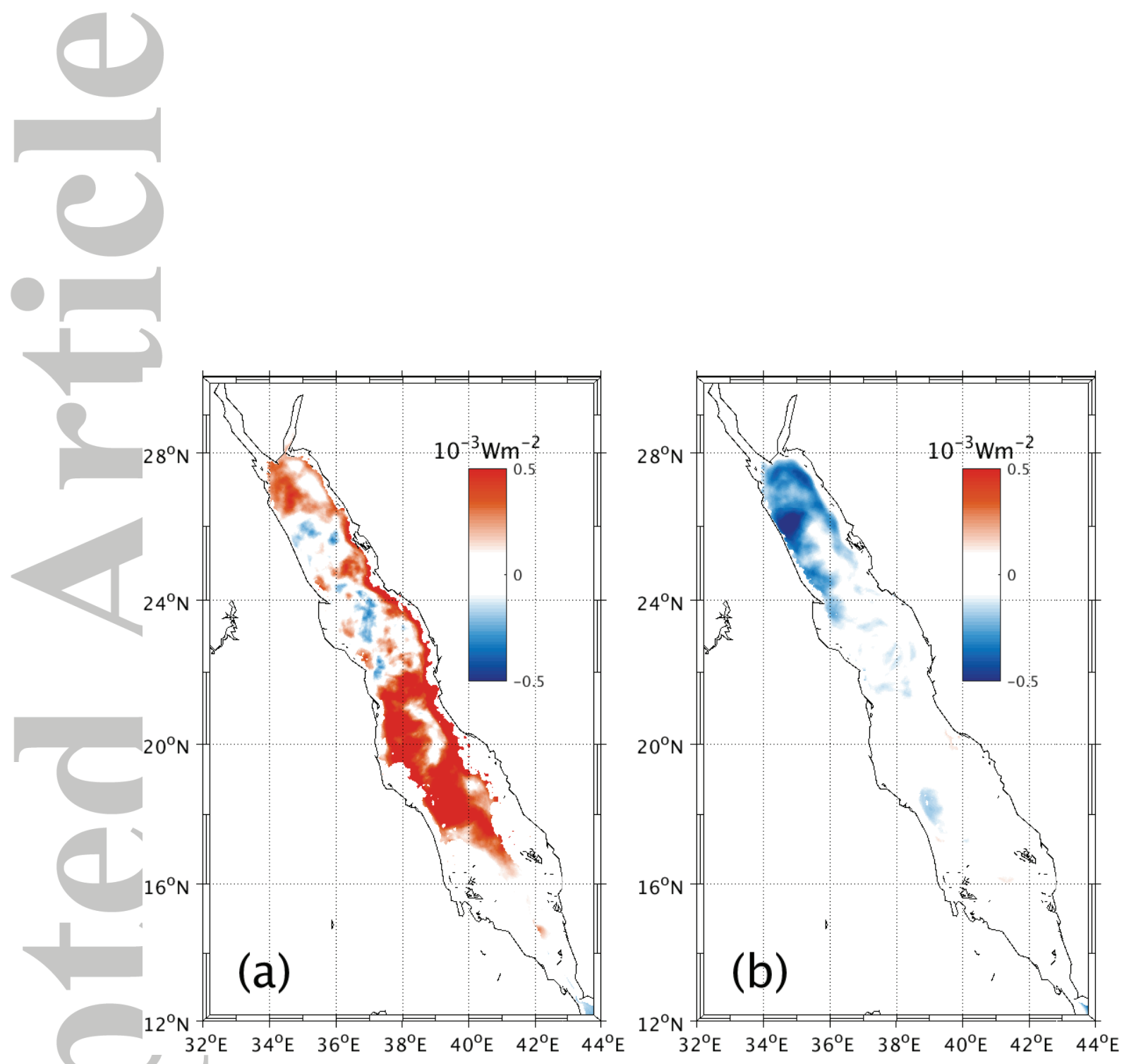

Figure 4. Distribution of the generation of EPE term, $\frac{g^{2}}{\overline{N^{2}} \rho_{0}}\left(\alpha_{s} \overline{\rho_{s}^{\prime} J_{s}^{\prime}}+\beta_{s} \overline{\rho_{s}^{\prime} G_{s}^{\prime}}\right)$, in (a) winter and (b) summer. Note that the color scale used in this figure is different from those in other figures. 

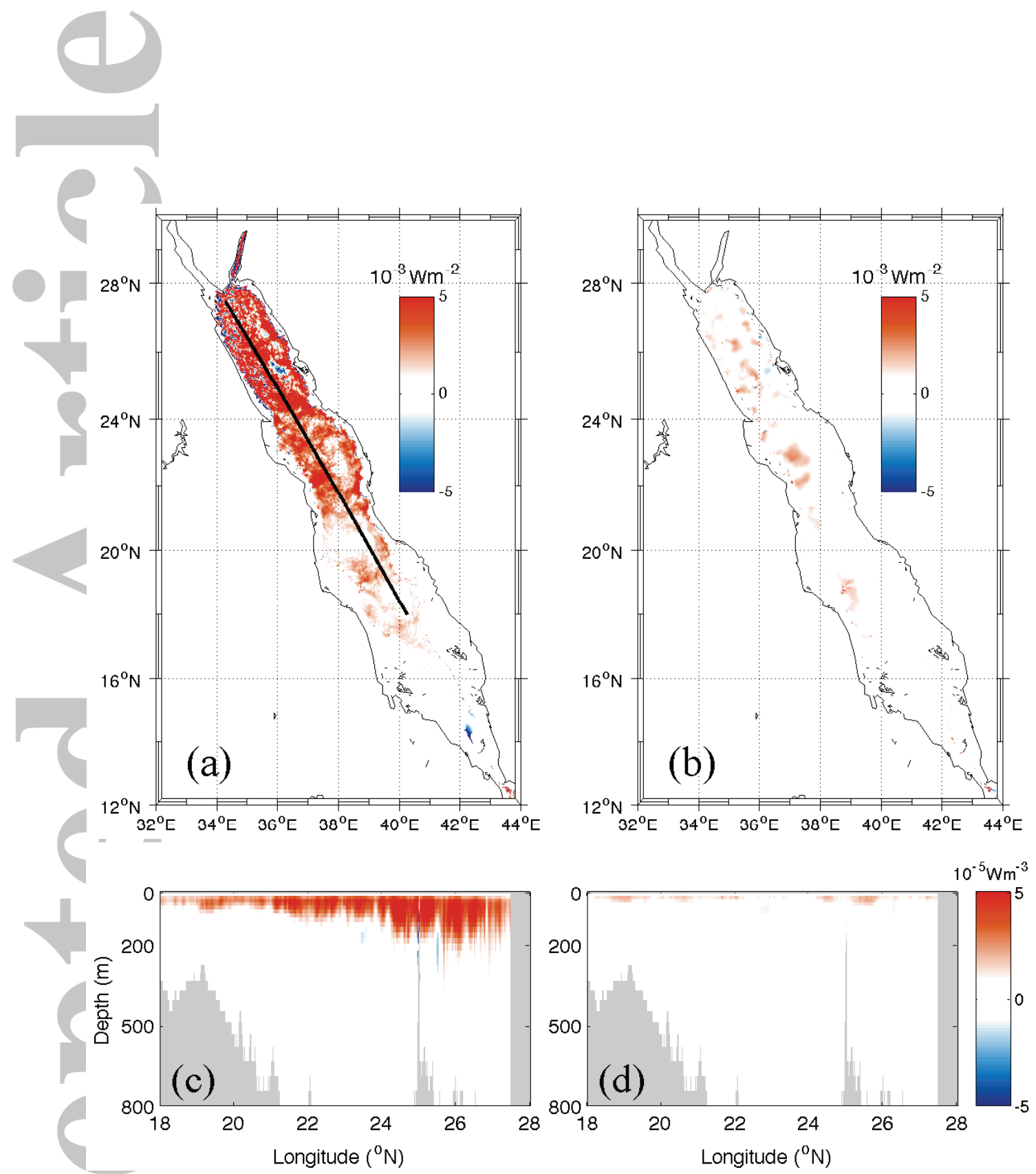

Figure 5. Distribution of the term $\left(-\overline{\rho^{\prime} w^{\prime}} g\right)$ integrated in the upper $200 \mathrm{~m}$ in (a) winter and (b) summer, and the vertical structure along a cross-section of the Red Sea axis (plotted as the black line in (a)) in (c) winter and (d) summer.

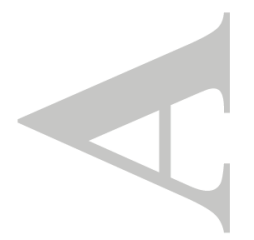



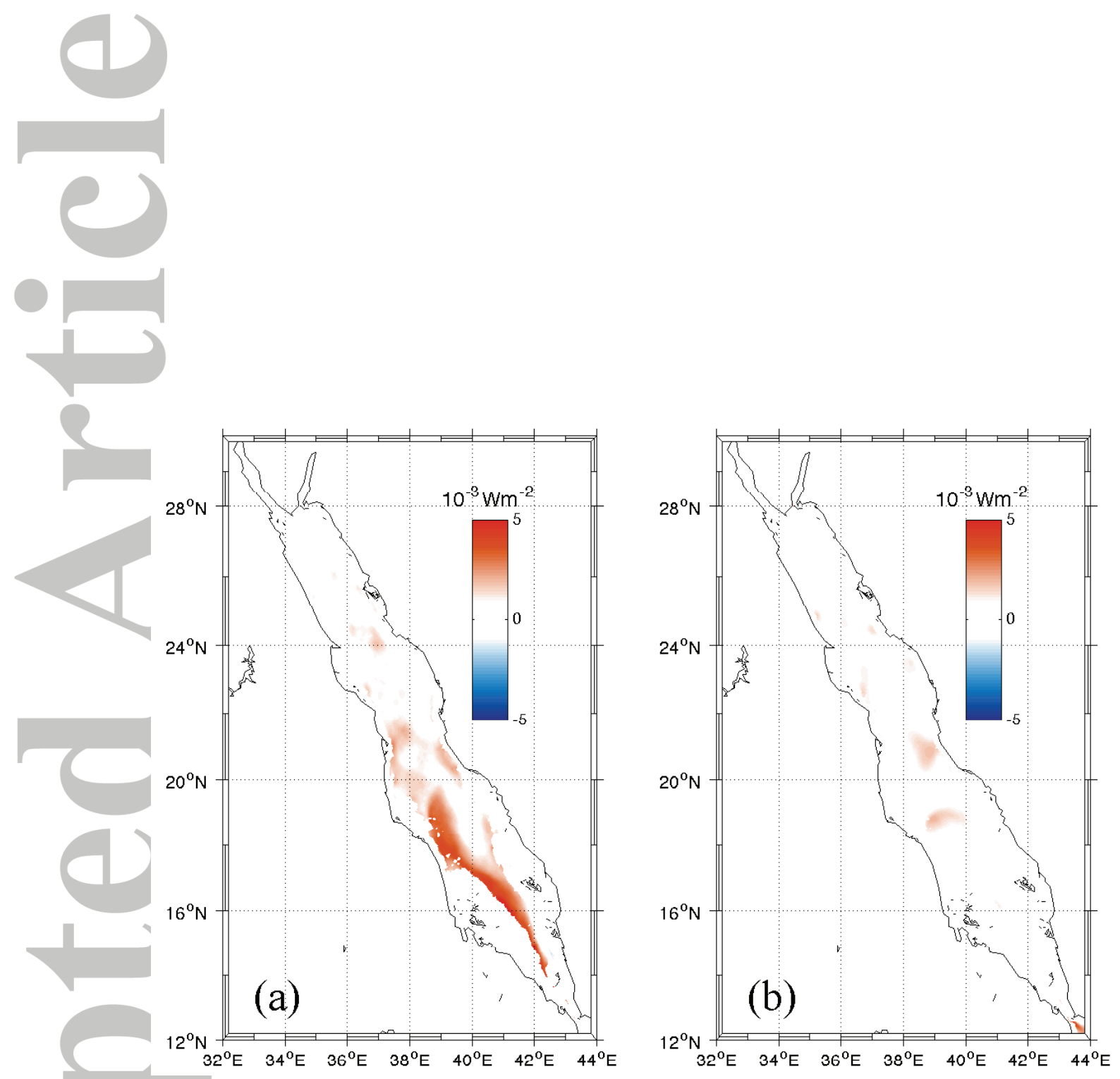

Figure 6. Distribution of generation of EKE due to surface power input by time-varying wind in (a) winter and (b) summer.

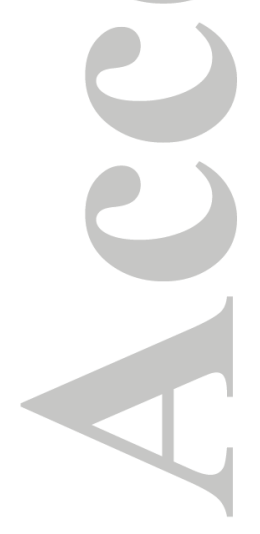




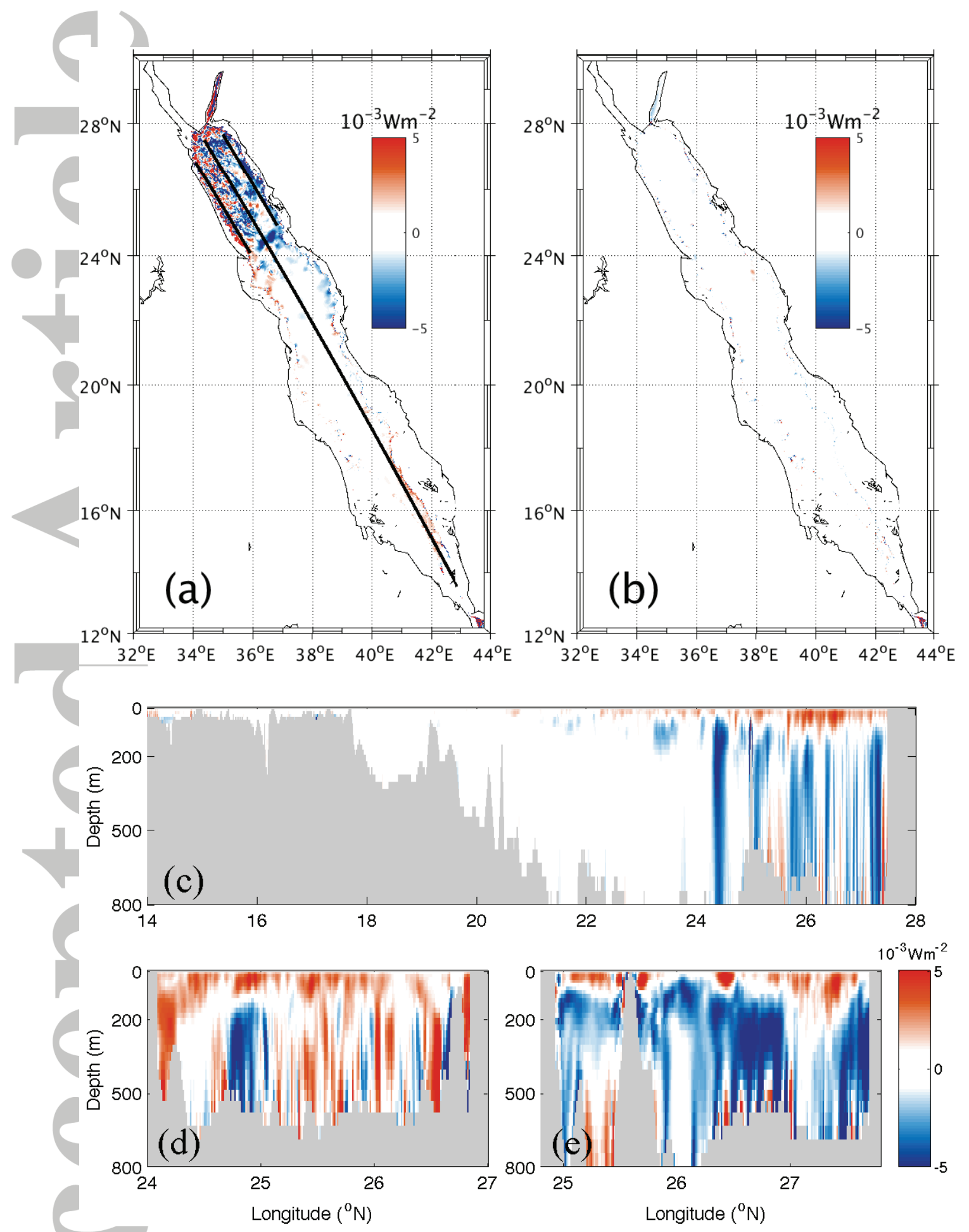

Figure 7. Distribution of the term, $\frac{\partial \overline{-p^{\prime} w^{\prime}}}{\partial z}$, integrated in the upper $200 \mathrm{~m}$ in (a) winter and (b) summer, and the vertical structure of $-\overline{p^{\prime} w^{\prime}}$ along (c) the Red Sea axis, (d) Egyptian coast and (e) northern Saudi coast, as represented by the black lines in (a). 

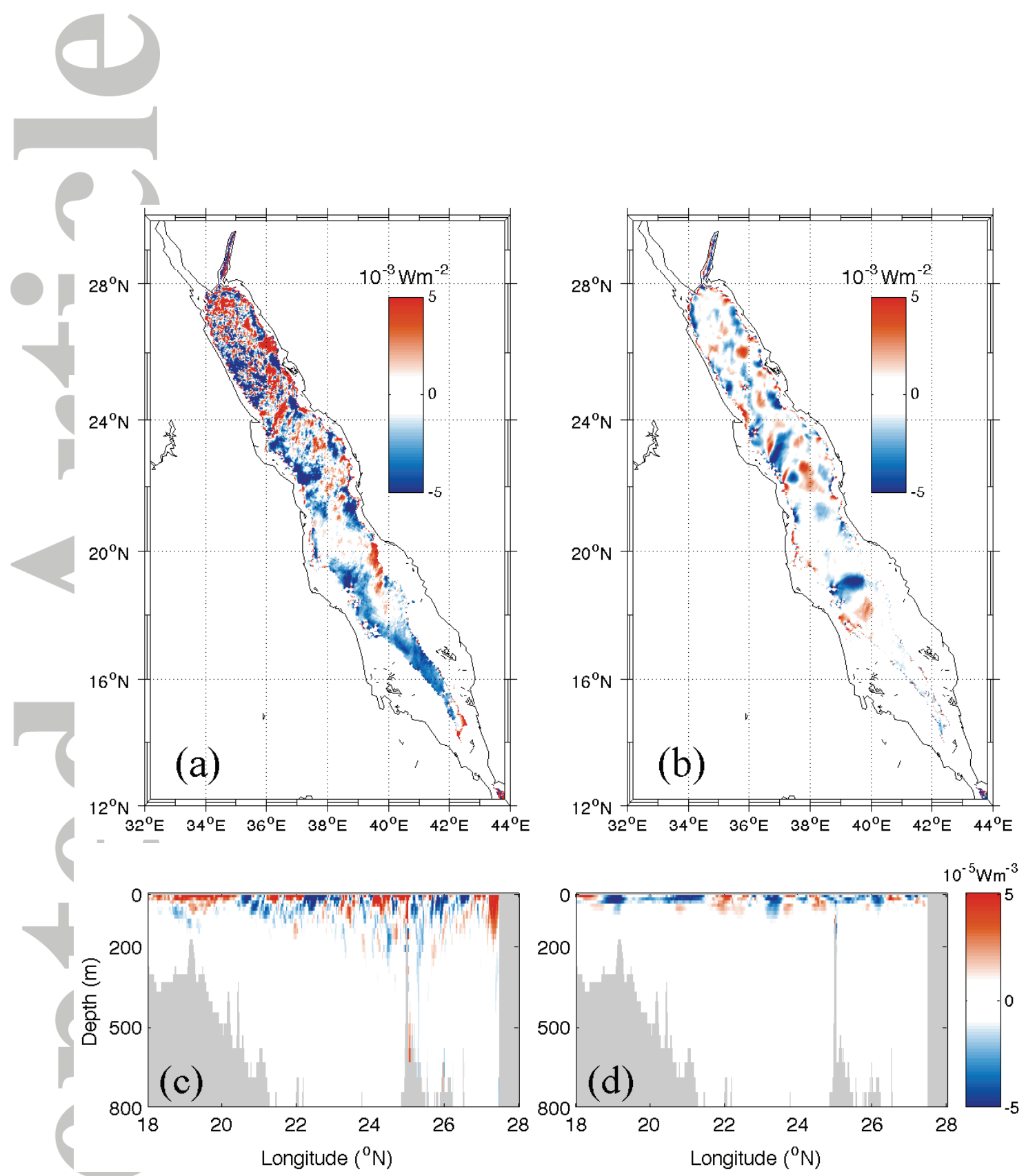

Figure 8. Distribution of the term, $-\left(\nabla_{h} \cdot \overline{p^{\prime} \mathbf{u}_{h}^{\prime}}+\frac{\rho_{0}}{2} \nabla \cdot \overline{\left(\mathbf{u} \cdot \mathbf{u}_{h}^{\prime 2}\right)}\right)$, integrated in the upper 200 $m$ in (a) winter and (b) summer, and the vertical structure along a cross-section of the Red Sea axis in (c) winter and (d) summer.

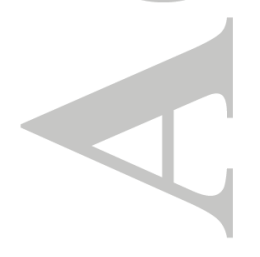



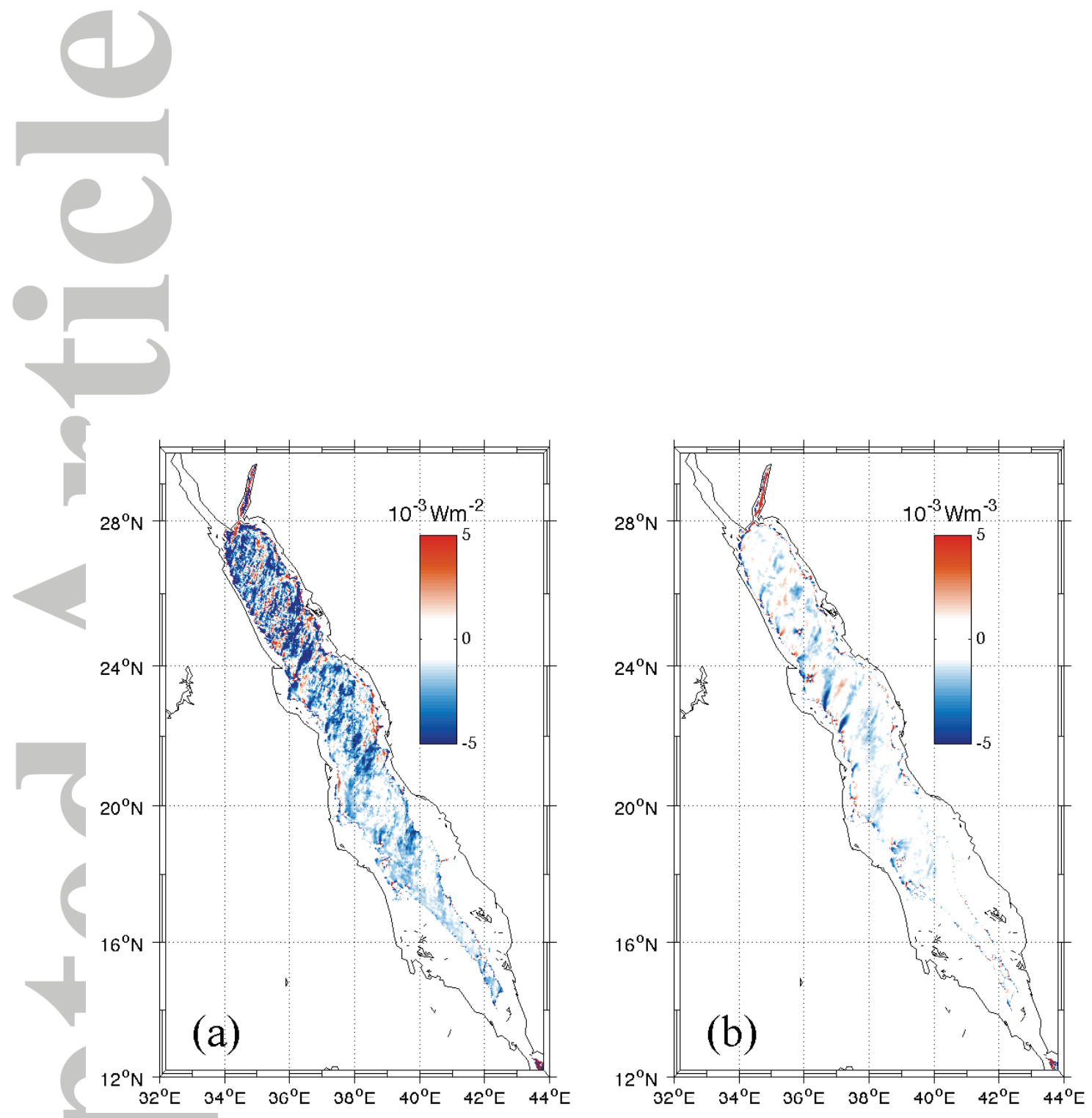

Figure 9. Distribution of the dissipation terms integrated in the upper $200 \mathrm{~m}$ in (a) winter and (b) summer.

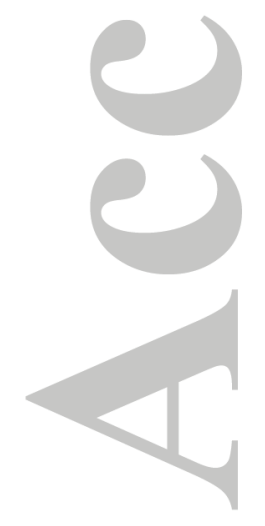



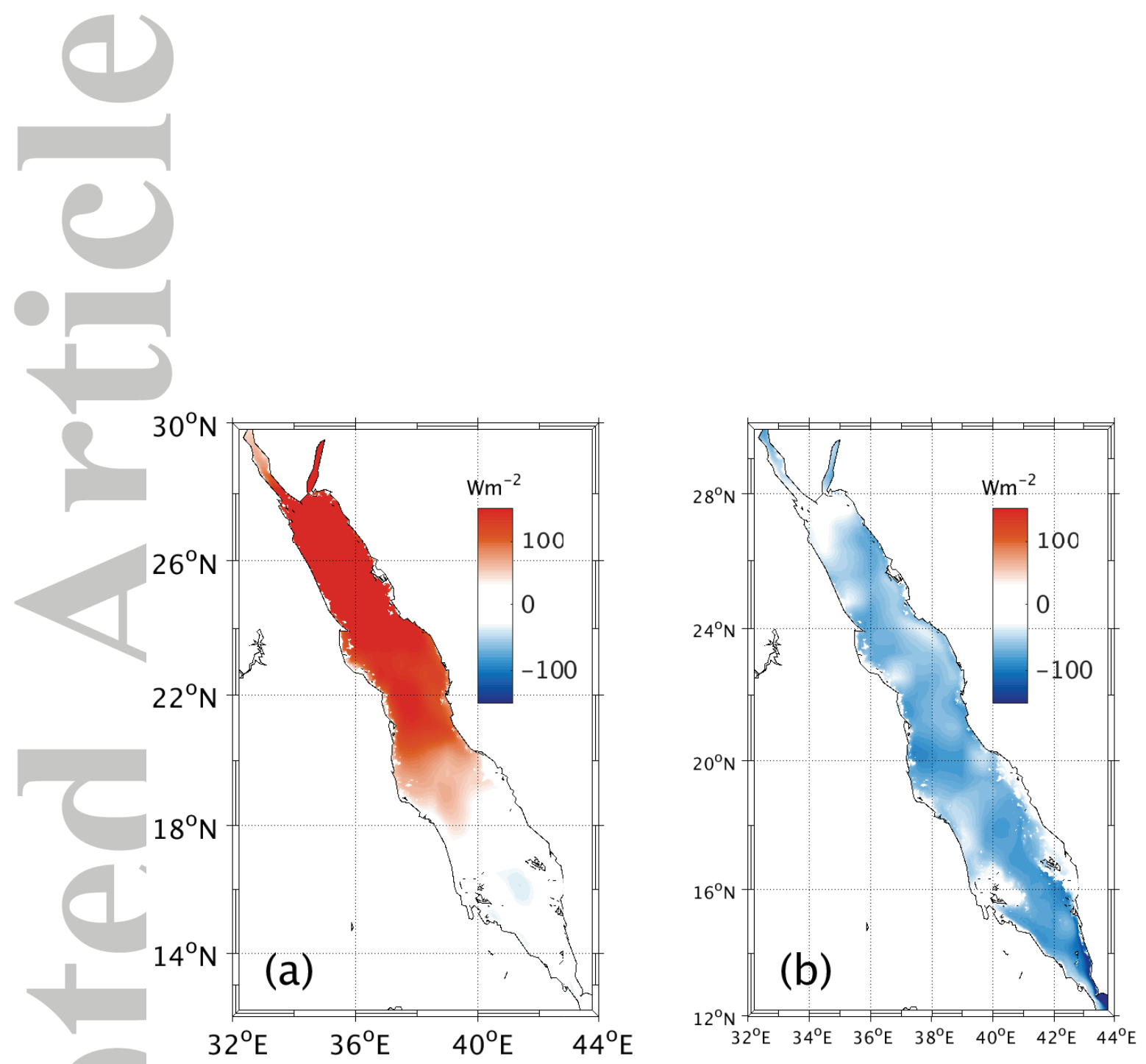

Figure 10. Seasonal mean surface net upward heat flux (sum of four components of flux including shortwave radiation, longwave radiation, latent heat and sensible heat) in (a) winter and (b) summer. Positive (negative) values indicate loss (gain) of heat from (to) the ocean.

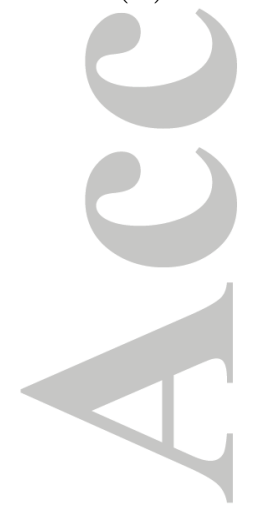

